\title{
Putative ammonia-oxidizing bacteria and archaea in an acidic red soil with different land utilization patterns
}

Jiao-Yan Ying, Li-Mei Zhang and Ji-Zheng He*

State Key Laboratory of Urban and Regional Ecology,

Research Center for Eco-Environmental Sciences,

Chinese Academy of Sciences, Beijing 100085, China.

\section{Summary}

Ammonia-oxidizers play a key role in nitrification, which is important for nitrogen cycling and soil function. However, little is known about how vegetation successions and agricultural practices caused by human activities impact the ammonia-oxidizers and nitrification process. Putative ammonia-oxidizing bacteria (AOB) and archaea (AOA) communities under different land utilization patterns of restoration (forest), degradation (pasture), cropland and pine plantation were analysed in an acidic red soil based on bacterial and archaeal amoA genes together with archaeal 16S rRNA gene. Real-time PCR, terminal restriction fragment length polymorphism (T-RFLP) and sequencing of clone libraries were conducted to study their abundance and community structure. Land utilization pattern showed significant effects on the copy numbers of all these genes, but only the bacterial amoA gene correlated significantly with potential nitrification rates (PNR). The cropland plot possessed the highest bacterial amoA gene copies and PNR, while the degradation plot was opposite to that. There were no significant variations in the bacterial amoA gene structure, which was dominated by Clusters 10 and 11 in Nitrosospira. However, archaeal amoA gene structure varied among different land utilization patterns especially for the cropland. The degradation plot was dominated by Crenarchaea 1.1crelated groups from which the amoA gene could not been amplified in this study, while other plots were dominated by Crenarchaea $1.1 \mathrm{a} / \mathrm{b}$ group based on archaeal 16S rRNA gene analysis. These results indicated significant effects of land utilization patterns on putative ammonia oxidizers, which were especially obvious in the degradation and cropland plots where frequent human disturbance occurred.

Received 13 March, 2009; accepted 3 December, 2009. *For correspondence. E-mail jzhe@rcees.ac.cn; Tel. (+86) 10 62849788; Fax (+86) 1062923563.

C 2010 Society for Applied Microbiology and Blackwell Publishing Ltd

\section{Introduction}

Ammonia-oxidation is the first and rate-limiting step of nitrification, which is a central process of the nitrogen cycle and is important in nitrogen loss and environmental problems such as green house gas emission and nitrate pollution (Kowalchuk and Stephen, 2001). For a long time, ammonia-oxidation had been considered to be catalysed mainly by the chemolithoautotrophic ammonia-oxidizing bacteria (AOB), which mainly composed of Nitrosomonas and Nitrosospira within $\beta$-proteobacteria in soils (Purkhold et al., 2000). However, in recent years, archaea were found to be potentially important in nitrification. Archaeal amoA gene was found more abundant than bacterial $a m o A$ gene in most aquatic and terrestrial environments (Francis et al., 2005; 2007; Leininger et al., 2006; Wuchter et al., 2006; He et al., 2007). A few strains of ammonia-oxidizing crenarchaeota (AOA) were isolated from a marine aquarium and hot springs (Könneke et al., 2005; de la Torre et al., 2008; Hatzenpichler et al., 2008), and strong correlations between $\mathrm{AOA}$ but not $\mathrm{AOB}$ abundance and ammonia oxidation rates were observed in several aquatic environments (Wuchter et al., 2006; Caffrey et al., 2007; Lam et al., 2007; Beman et al., 2008). Expression of archaeal amoA gene increased with elevated ammonia concentrations in an agricultural soil (Treusch et al., 2005), but less correlations of AOA than $A O B$ to nitrification rate were found in some recent studies (He et al., 2007; Le Roux et al., 2008; Nicol et al., 2008; Shen et al., 2008). AOA have not been isolated from soil, and it is important to link $A O A$ and $A O B$ community composition with nitrification activity and other factors in more systems to understand their physiological characteristics and functions due to the difficulty of isolation.

Agricultural practices and vegetation successions caused by human activities can have significant effects on soil properties and functions including $\mathrm{N}$ mineralization and nitrification (Compton and Boone, 2000; Carney et al., 2004), while the effects on ammonia oxidizers have rarely been studied. Abundance and/or community structure of $\mathrm{AOB}$ responded to a variety of environmental factors such as $\mathrm{pH}$, ammonia concentration, $\mathrm{N}$-containing fertilizers (Prosser and Embley, 2002), and AOB have become a model system for molecular microbial ecology and been used as an indicator organism widely (Kowalchuk and Stephen, 2001, Horz et al., 2004). Nevertheless, little 
study focus on the effect of clear-cutting and cultivation of forest on $A O B$, and even less were studied in a small-scale field with other constant conditions. Some studies determined the abundance of $A O B$ with cultivation-based methods, which possess significant bias compared with molecular methods (Phillips et al., 2000). In contrast with the narrow phylogeny of $A O B$, more diverse $A O A$ have been found, which may be related to diverse physiological characteristics. Some recent research reported the impacts of $\mathrm{pH}$, temperature, tree type, fertilizer and grazing on them in soils together with $\mathrm{AOB}$ communities (He et al., 2007; Boyle-Yarwood et al., 2008; Le Roux et al., 2008; Nicol et al., 2008; Shen et al., 2008; Tourna et al., 2008), and both $\mathrm{AOA}$ abundance and community structure were found sensitive to most of these factors. However, the response of $A O A$ to agriculture practices and vegetation successions is scarcely studied.

Low nutrient acidic red soils exist extensively in southern China where $\mathrm{N}$ fertilization happened widely; therefore, it is important to understand the anthropic effect on nitrification in red soils both for primary production and environmental pollution. A long-term ecological station was established in 1995 in a Chinese red soil with different land utilization patterns, and provided ideal samples to study the effect of cultivation and vegetation successions on soil properties. Based on their potential importance as both catalysers and indicators, abundance and community structure of $A O B$ and $A O A$ were investigated together with potential nitrification rate (PNR), and the association of $A O B$ and $A O A$ with nitrification and related factors were analysed. The $\alpha$-subunit of ammonia monooxygenase gene $(a m o A)$ was used as biomarker for both $\mathrm{AOB}$ and $A O A$. Most AOA groups were found associated with the $1.1 \mathrm{a}$ and $1.1 \mathrm{~b}$ lineages based on amoA and ribosomal gene analysis, but some other distant groups were also found recently such as the ALOHA group (or pSL12-like group) and Nitrosocaldus yellowstonii group, and indicated broad phylogeny of AOA in Crenarchaeota (Mincer et al., 2007; de la Torre et al., 2008; Prosser and Nicol, 2008). Nevertheless, there is no information about the amoA gene within Crenarchaeota 1.1c-related groups, which is abundant in some acidic soils (Kemnitz et al., 2007; Nicol et al., 2007). Therefore, in addition to the amoA genes, 16S rRNA gene of archaea was also analysed to provide more information about the phylogeny of AOA and to reduce the possible bias by PCR primers.

\section{Results and discussion}

\section{Site description and sampling}

The long-term ecological system was located at a slope field of Taoyuan Experimental Station of the Chinese Academy of Sciences, with elevation of 95-125 m at
$\mathrm{E} 111^{\circ} 26^{\prime}$ and $\mathrm{N} 28^{\circ} 55^{\prime}$, Hunan province, China. The vegetations were removed in 1995 and the field was divided into different plots for establishing different land utilization patterns. The restoration plot $(\mathrm{R})$ is wooded with diverse vegetations without human disturbance. Vegetations in the degradation plot (D) were harvested and moved away in May and November every year, thus only short grass were grown. The cropland $(C)$ and pine $(P)$ plots were divided into 15 terraces. The cropland plot was planted with different crops in different seasons, and normal agricultural management such as fertilization and tillage were employed. The pine plot was scarcely disturbed after plantation. Soil samples were collected in Autumn (October) of 2007 from three positions designated as upper $(\mathrm{U})$, middle $(\mathrm{M})$ and lower $(\mathrm{L})$ places, which were parallel to the third, eighth and thirteenth terrace in the slope, respectively, to avoid the effect of landform to give reliable assessment of land utilization patterns.

These samples were named by combining their land utilization pattern (R, D, C, P) and position ( $U, M, L)$. For instance, samples from upper, middle and lower positions of the restoration plot were named $\mathrm{RU}, \mathrm{RM}$ and $\mathrm{RL}$, respectively. Since there was no replicate of plot, three parallels were done for DNA extraction, PNR and nitrate analysis.

\section{PNR and soil chemical properties}

All these parameters were measured according to Shen and colleagues (2008). As shown in Table 1, variations of soil properties were quite small among different positions in the same plot when compared with those among different plots. Thus, data from different positions were regarded as replicates for statistic analysis since there is no replicate of plot. PNR was highest in the cropland plot (> 6 pmol day ${ }^{-1} \mathrm{~g}^{-1}$ soil) and lowest in the restoration and degradation plot $\left(<1\right.$ pmol day $^{-1} \mathrm{~g}^{-1}$ soil). Nitrate concentration was highest in the cropland, then followed by the pine plot, the restoration plot, and was lowest in the degradation plot. Both the $\mathrm{pH}$ value and organic matter content in the degradation plot were higher than the cropland and pine plots. PNR correlated $(n=12)$ positively with nitrate concentration $(r=0.950, P<0.001)$ and negatively with organic matter content $(r=-0.696, P<0.05)$ and $\mathrm{pH}$ value $(-0.673, P<0.05)$, which suggested that nitrification is possibly related to mineralization and contributed to acidification in these plots.

\section{Abundance of $A O B, A O A$ and archaea}

DNA extraction and real-time PCR analysis of amoA gene were done according to Shen and colleagues (2008), while real-time PCR analysis of the archaeal 16S rRNA were detected with primers Ar4F (Hershberger et al., 1996) and Ar958R (Delong, 1992). 
Table 1. Potential nitrification rate (PNR) and soil chemical properties with different land utilization patterns and positions.

\begin{tabular}{|c|c|c|c|c|}
\hline Sample & $\begin{array}{l}\text { PNR } \\
\text { (n mol d }{ }^{-1} \mathrm{~g}^{-1} \text { soil) }\end{array}$ & $\begin{array}{l}\mathrm{NO}^{-}-\mathrm{N} \\
\left(\mathrm{mg} \mathrm{N} \mathrm{kg}^{-1} \text { soil) }\right.\end{array}$ & $\mathrm{pH}$ & $\begin{array}{l}\text { Organic matter } \\
\left(\mathrm{g} \mathrm{kg}^{-1} \text { soil) }\right.\end{array}$ \\
\hline$R U^{a}$ & $1.05 \pm 0.09^{b}$ & $13.7 \pm 0.2$ & 4.17 & 16.7 \\
\hline RM & $0.90 \pm 0.12$ & $13.3 \pm 0.1$ & 4.23 & 16.5 \\
\hline \multirow[t]{2}{*}{$\mathrm{RL}$} & $1.14 \pm 0.28$ & $12.1 \pm 0.2$ & 4.26 & 14.9 \\
\hline & $a^{c}$ & $\mathrm{~b}$ & $\mathrm{bc}$ & b \\
\hline DU & $0.63 \pm 0.10$ & $1.33 \pm 0.37$ & 4.33 & 19.9 \\
\hline DM & $0.32 \pm 0.00$ & $0.53 \pm 0.09$ & 4.33 & 14.0 \\
\hline \multirow[t]{2}{*}{$\mathrm{DL}$} & $0.73 \pm 0.30$ & $0.47 \pm 0.14$ & 4.33 & 14.8 \\
\hline & a & $a$ & c & $\mathrm{b}$ \\
\hline $\mathrm{CU}$ & $6.01 \pm 0.30$ & $51.4 \pm 0.9$ & 3.95 & 11.2 \\
\hline $\mathrm{CM}$ & $6.15 \pm 0.07$ & $45.3 \pm 1.4$ & 4.14 & 9.50 \\
\hline \multirow[t]{2}{*}{$C L$} & $7.28 \pm 0.80$ & $45.4 \pm 0.7$ & 4.16 & 12.7 \\
\hline & c & $\mathrm{d}$ & a & a \\
\hline PU & $1.52 \pm 0.04$ & $18.7 \pm 0.6$ & 4.14 & 14.6 \\
\hline PM & $2.30 \pm 0.35$ & $18.5 \pm 0.4$ & 4.12 & 11.6 \\
\hline \multirow[t]{2}{*}{ PL } & $3.23 \pm 0.47$ & $16.4 \pm 0.6$ & 4.07 & 15.6 \\
\hline & $\mathrm{b}$ & c & $a b$ & $a b$ \\
\hline
\end{tabular}

a. First letter of sample name means land utilization patterns of restoration $(R)$, degradation $(D)$, cropland $(C)$ and pine plantation $(P)$, while the second letter means the upper $(\mathrm{U})$, middle $(\mathrm{M})$ and lower $(\mathrm{L})$ positions in the plot.

b. Mean \pm SD $(n=3)$. Standard deviations for $\mathrm{pH}$ and organic matter were below 0.05 and $1 \mathrm{~g} \mathrm{~kg}^{-1}$ soil respectively.

c. Letters indicate significant differences of different land utilization patterns with $P=0.05$ based on General Linear Model analysis. Data from different positions of the same plot were used as three replicates.

Ammonia-oxidizing bacteria abundance (amoA gene copy number) was highest in the cropland plot $\left(10^{5}-10^{6}\right.$ copies $\mathrm{g}^{-1}$ soil) and lowest in the degradation plot, which is below the detection limit of $1.2 \times 10^{3}$ copies $\mathrm{g}^{-1}$ soil (Fig. 1), and showed a trend similar to PNR and nitrate concentration. Neglecting data from the degradation plot, AOB abundance still correlated positively with PNR ( $r=0.718, P<0.05, n=9)$ as happened in some other studies (He et al., 2007; Shen et al., 2008) and also with nitrate concentration $(r=0.728, P<0.05, n=9)$, which suggested a potential important role of $A O B$ in nitrification. The increased AOB abundance, PNR and nitrate concentration in the cropland plot are possibly related to $\mathrm{N}$-containing fertilizer applications according to Shen and colleagues (2008). Besides that, tillage might also increase nitrification rates (Bruns et al., 1999). Contrary to the cropland, the degradation plot possessed the lowest AOB abundance (not detected), PNR and nitrate concentration. To our knowledge, this is the first report about decrease of $\mathrm{AOB}$ abundance caused by clear-cutting of vegetation. Accelerated $\mathrm{N}$ mineralization in cultivated soils and lower $\mathrm{N}$ mineralization in pasture than forest were found in some other studies (Compton and Boone, 2000; Carney et al., 2004), which might related to the shifts of $A O B$ abundance in the cropland and degradation plots. Compared with the great change caused by cultivation and reduced vegetation biomass in the cropland and degradation plot respectively, AOB abundance, PNR and nitrate concentration showed much less differences between the restoration and the pine plots, and showed little effect of tree type on these nitrification related parameters.

Ammonia-oxidizing archaea abundance (amo $A$ gene copy number) was highest in the restoration and pine plots $\left(10^{7}-10^{8}\right.$ copies $\mathrm{g}^{-1}$ soil), followed by the cropland plot, and lowest in the degradation plot $\left(10^{4}-10^{6}\right.$ copies $\mathrm{g}^{-1}$ soil). The AOA copy numbers were always higher than AOB as reported in most other environments (Leininger et al., 2006; He et al., 2007; Chen et al., 2008). Archaea abundance (16S rRNA gene copy number) changed much less

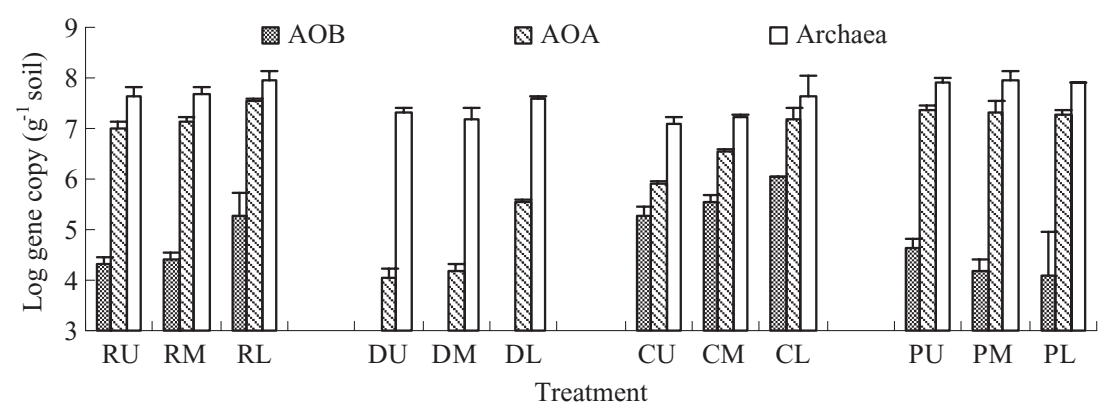

Fig. 1. Abundance of $A O B$ (bacterial $a m o A)$, AOA (archaeal $a m o A)$ and archaea (16S rRNA gene). First letter of sample name means land utilization patterns of restoration $(R)$, degradation (D), cropland (C) and pine plantation $(P)$, while the second letter means the upper $(\mathrm{U})$, middle $(\mathrm{M})$ and lower $(\mathrm{L})$ positions in the plot. 
$\left(10^{7}-10^{8}\right.$ copies $\mathrm{g}^{-1}$ soil) compared with the results based on the archaeal amoA gene, and it was higher in the restoration and pine plots than in the degradation and cropland plots $(P<0.05)$. In most cases, ratios of archaeal 16S rRNA and amoA gene copy numbers were near 3 , but it is particularly high in the degradation plot, which is above 1000 at the upper and middle position.

Different from $A O B$, there was no significant correlation between PNR and AOA or archaea abundance. Strong correlations between $A O A$ rather than $A O B$ abundance and nitrification were found in several aquatic environments (Wuchter et al., 2006; Caffrey et al., 2007; Lam et al., 2007; Beman et al., 2008), which suggested an important role of archaea in nitrification. However, it was rarely reported in soils where the abundance or transcription activity of $A O B$ showed correlation to nitrification more closely than AOA in most studies (Nicol et al., 2008; Shen et al., 2008). Congruent with this, Jia and Conrad (2009) and Di and colleagues (2009) recently showed that bacteria rather than archaea were important for ammonia oxidation in some agricultural and pasture soils. Thus, the significance of archaea in nitrification in soil is doubtful. Metagenomic analysis indicated the potential metabolic capacity for heterotrophic growth of amoA-contaning archaea (Hallam et al., 2006). Whether they play an active role in nitrification in soil or they function in specific conditions, for example in nutrient-limited aquatic environments, is still unclear.

\section{Community structure and phylogeny of bacterial amoA gene}

For clone libraries construction, primers of archaeal amo $A$ and 16S rRNA gene were the same as used for real-time $\mathrm{PCR}$, while the bacterial $a m o A$ gene was amplified by primers amoA-1F and amoA-2R (Rotthauwe et al., 1997), and primers for terminal restriction fragment length polymorphism (T-RFLP) analysis were the same with the forward primers labelled by 6-FAM. The neighbour-joining phylogenetic trees were conducted with Kimura 2-parameter distance with MEGA version 3.0 (Kumar et al., 2004).

There was only one dominant terminal restriction fragment (T-RF) of bacterial amoA gene at $109 \mathrm{bp}$ in all samples except the degradation plot where T-RF could not be detected because of the low AOB abundance. Thus clones from the middle position of the other three plots were sequenced to investigate the dominant groups. All the $A O B$ sequences belonged to the Nitrosospira group (Fig. 2). Most sequences in each plot were affiliated to clusters 10 and 11 based on the classification of Avrahami and Conrad (2003) and Chen and colleagues (2008), and contained a T-RF size of $109 \mathrm{bp}$. Most sequences shared more than $99 \%$ similarity with the clones from Qiyang station in Hunan Province such as QY-A17 (He et al., 2007). A few remaining sequences were affiliated with clusters $3 a$ and 4 . Sequences falling into cluster $3 a$ were further divided into $3 a 1$ and $3 a 2$ due to their unstable affiliations.

\section{Community structure and phylogeny of archaeal amoA}

The T-RFLP analysis of the archaeal amoA gene showed great variations among different utilization patterns (Fig. 3). The cropland plot had a single T-RF of $331 \mathrm{bp}$. While in other plots, T-RFs of 372 and 423 bp dominated in most samples. In addition, $310 \mathrm{bp}$ T-RFs were detected in all samples from the restoration plot.

A total of 45 and 14 clones of archaeal amoA gene from the middle position of restoration and cropland plots, respectively, were sequenced for phylogenetic analysis of main groups (Fig. 4). Sequences from the restoration or cropland plot fell into a distinct clade which was designated as $\mathrm{R}$ or $\mathrm{C}$ cluster, respectively, except that there was one sequences (AOA-R81) fell into the soil/sediment group. Sequences of $R$ cluster contained T-RFs of 310 , 372 or $423 \mathrm{bp}$, while sequences of $\mathrm{C}$ cluster had a T-RF of $331 \mathrm{bp}$ when restricted by $\mathrm{Mbol}$, according with the T-RFLP analysis. Combining the T-RFLP and phylogenetic analysis, archaeal amoA genes were composed of $\mathrm{C}$ cluster in the cropland plot but dominated by $\mathrm{R}$ cluster in other plots. Whether the high content of $\mathrm{C}$ cluster is related to the high PNR in the cropland plot needs further study. He and colleagues (2007) also reported changes of $A O A$ but not $A O B$ community structure responding to different fertilizers in acid red soil. This study further showed sensitivity of AOA to cultivation in red soils which reflected their diverse physiology and suggested a potential role of $\mathrm{AOA}$ as indicator of certain environmental factors.

Similar to AOB, most sequences showed high similarities (> 99\%) to the clones from Qiyang station in the same province such as QY-A39 and QY-A40, and suggested significant influence of geography or soil type on phylogeny of $A O A$ and $A O B$ as on bacterial community structure reported by $\mathrm{Ge}$ and colleagues (2008). An interesting result was that, sequences of Qiyang station which fell into the $\mathrm{R}$ or $\mathrm{C}$ clusters were cloned from samples with $\mathrm{pH}<5$ ( $\mathrm{He}$ et al., 2007). Some other sequences from acidic soils such as CSamoA-29-4.9 (Nicol et al., 2008) and AOAC-u_sC07 (Hansel et al., 2008) also clustered tightly with $\mathrm{R}$ and $\mathrm{C}$ clusters. All these sequences formed a lineage which was related but outside of the marine cluster, and were affiliated with the 1.1a-associated group, which was related to acidic condition according to Nicol and colleagues (2008). These results suggested that the $1.1 \mathrm{a}$-associated group may be associated with acidic environment widely. 


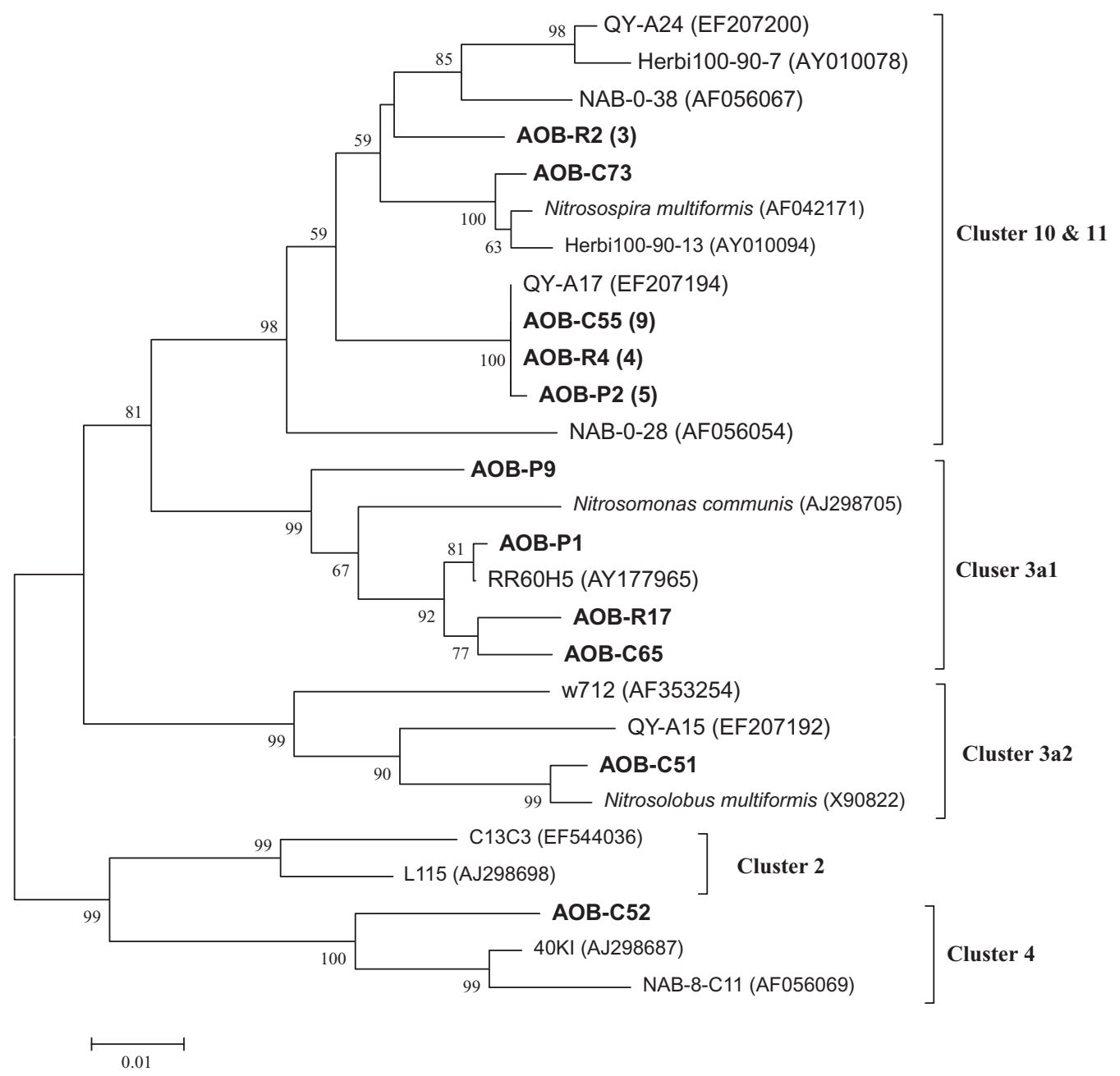

Fig. 2. Neighbour-joining phylogenetic tree of bacterial $a m o A$ gene from a Chinese red soil. Clones from this study were shown in bold with name AOB followed by letter R, C or P from the restoration, cropland and pine plots respectively. Number in parentheses after the clone names from this study showed the number of clones from the same sample with similarities above $99 \%$ to the listed sequence.

\section{Community structure and phylogeny of archaeal} $16 S$ rRNA gene

The T-RFLP analysis of archaeal 16S rRNA gene showed that the degradation plot was dominated by 350,352 and 201 bp T-RFs, while other plots were dominated by 322 bp T-RF (Fig. 5). The proportion of 322 bp T-RF was less than $10 \%$ in the degradation plot, while above $50 \%$ in other plots and proportions of $201 \mathrm{bp}$ and $352 \mathrm{bp}$ T-RFs in the degradation plot were higher than other plots.

A total of 44 and 37 clones of 16S rRNA gene from the middle position of the restoration and degradation plots, respectively, were subjected to sequence analysis (Fig. 6). Most sequences belonged to Crenarchaeota with only three sequences affiliated with Euryarchaeota in each plot. More than half of the sequences from the

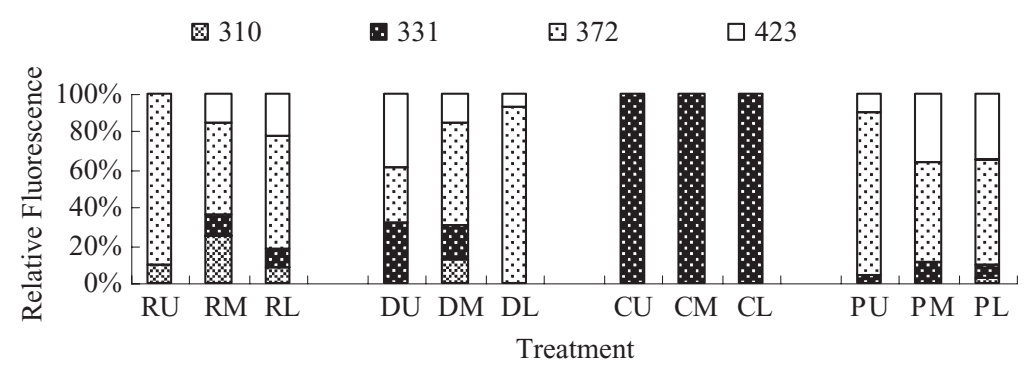

Fig. 3. Relative abundance of T-RFs of archaeal $a m o A$ gene restricted by Mbol with different land utilization patterns and positions. First letter of sample name means land utilization patterns of restoration $(R)$, degradation (D), cropland (C) and pine plantation $(\mathrm{P})$, while the second letter means the upper $(\mathrm{U})$, middle $(\mathrm{M})$ and lower $(\mathrm{L})$ positions in the plot. 


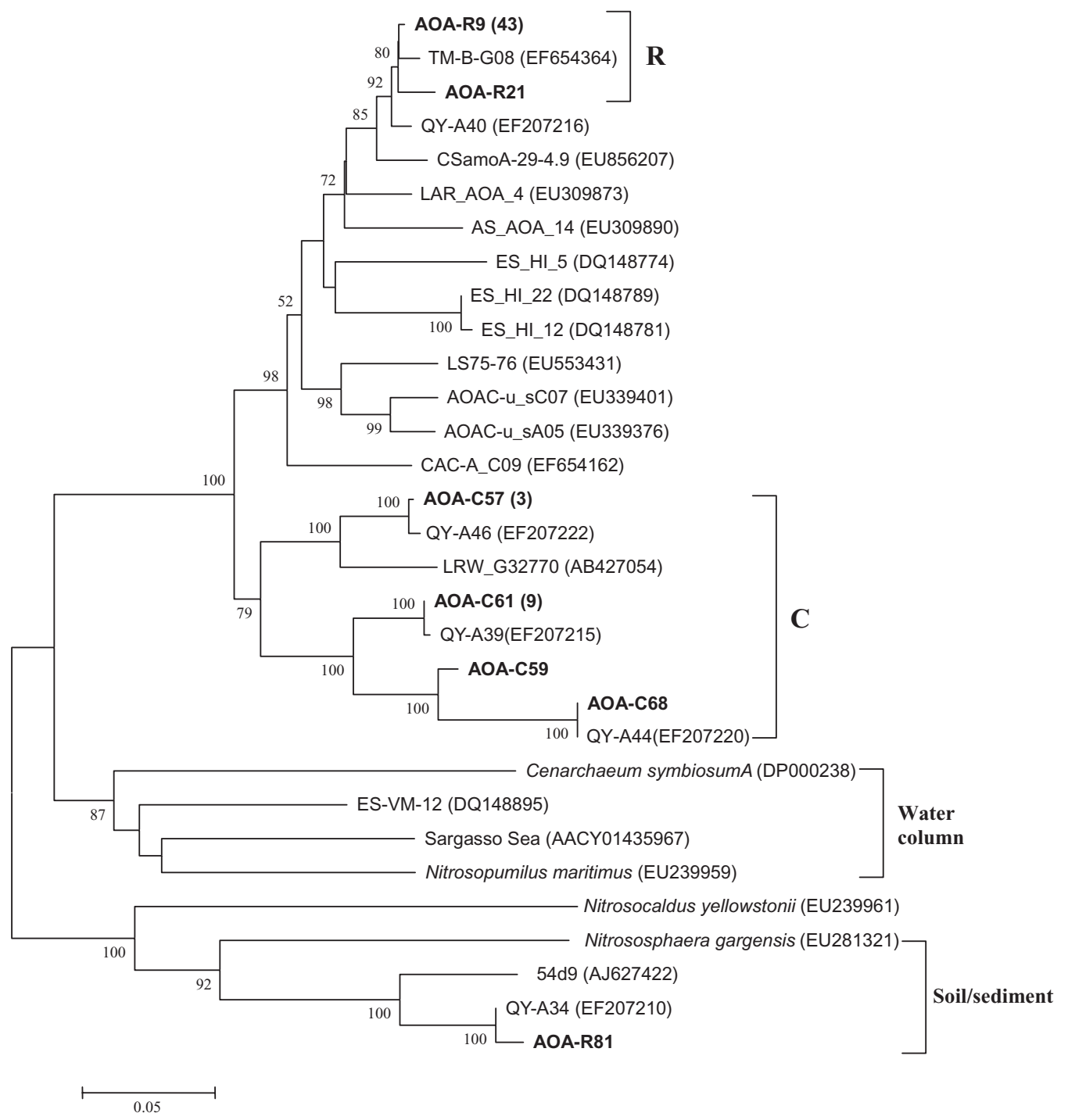

Fig. 4. Neighbour-joining phylogenetic tree of archaeal $a m o A$ gene from a Chinese red soil. Clones from this study were shown in bold with name $A O A$ followed by letter $\mathrm{R}$ or $\mathrm{C}$ from the restoration and cropland plots respectively. Number in parentheses after the clone names from this study showed the number of clones from the same sample with similarities above $99 \%$ to the listed sequence.

restoration plot clustered together with soil clone MFT1-C2 and fell into the 1.1a-associated group in congruence with archaeal $a m o A$ gene analysis as reported by Nicol and colleagues (2008), and indicated the coevo- lution of amoA and 16S rRNA gene of this cluster. The $1.1 \mathrm{a}, 1.1 \mathrm{~b}$ and 1.1a-associated sequences formed a tight clade, which was called as $1.1 \mathrm{a} / \mathrm{b}$ group. On the contrary, the degradation plot was dominated by the

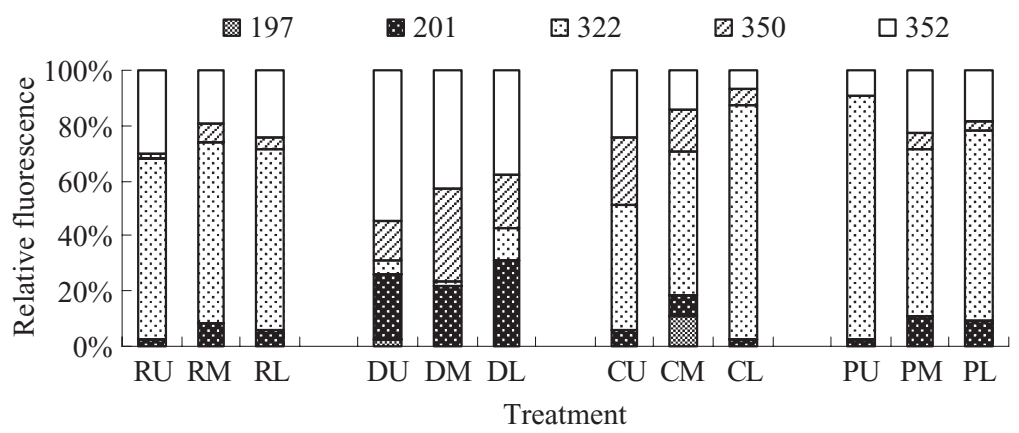

Fig. 5. Relative abundance of T-RFs of archaeal $16 \mathrm{~S}$ rRNA gene restricted by Hhal with different land utilization patterns and positions. First letter of sample name means land utilization patterns of restoration $(\mathrm{R})$, degradation (D), cropland $(C)$ and pine plantation $(P)$, while the second letter means the upper $(\mathrm{U})$, middle $(\mathrm{M})$ and lower $(\mathrm{L})$ positions in the plot. 


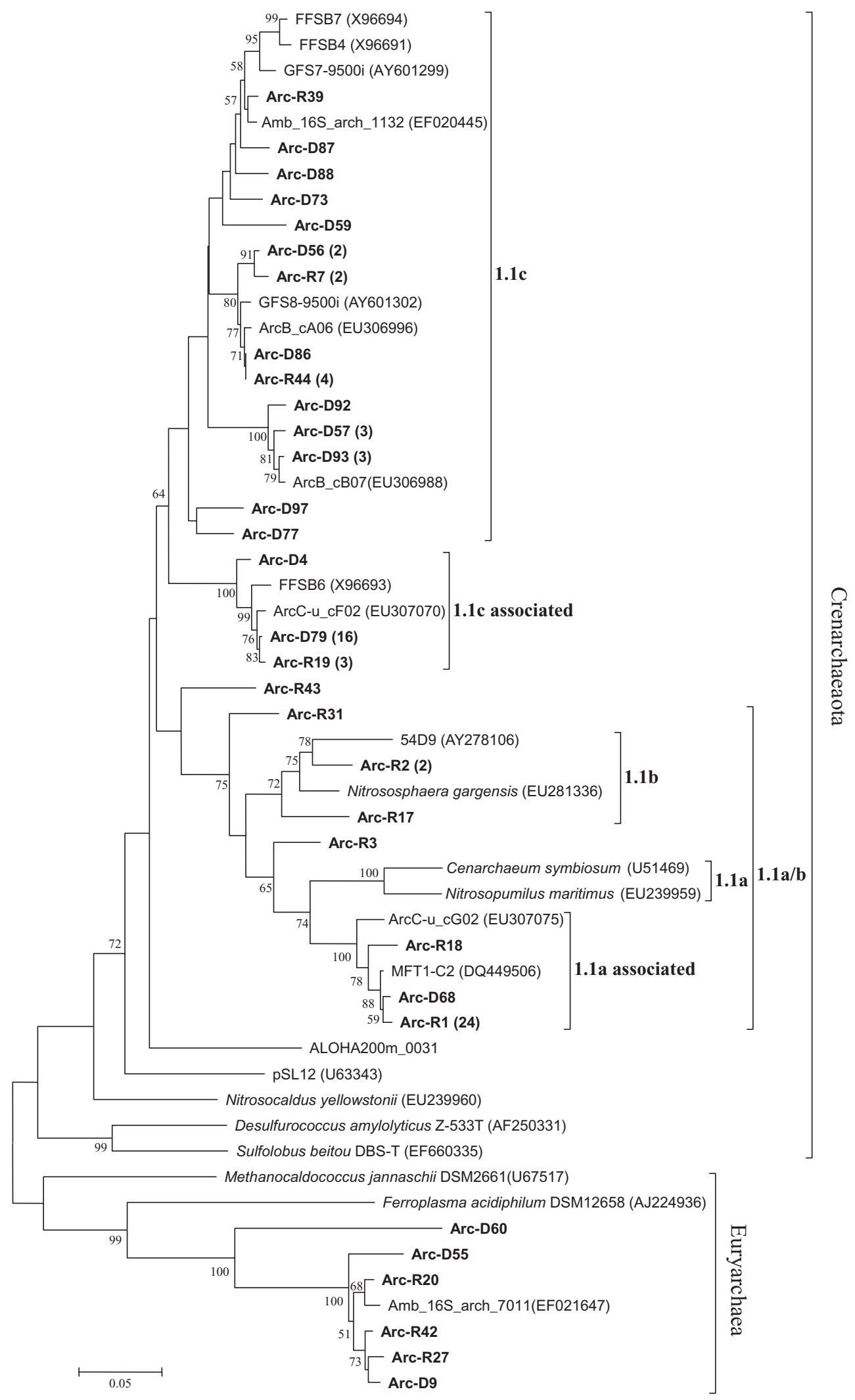

Fig. 6. Neighbour-joining phylogenetic tree of archaeal 16S rRNA gene from a Chinese red soil. Clones from this study were shown in bold with name Arc followed by letter R or D from the restoration and degradation plots respectively. Number in parentheses after the clone names from this study showed the number of clones from the same sample with similarities above $99 \%$ to the listed sequence. 
1.1c and 1.1c-associated (it was designated as 1.1d in some documents because of its unstable affiliation with 1.1c group) groups with only one sequence falling into the 1.1a-associated group. Considering the high ratios of archaeal 16S rRNA to amoA gene copy numbers in the degradation plot, it was indicated that amoA genes were not amplified from group 1.1c or 1.1c-associated. Similarly, according to Hansel and colleagues (2008), the 1.1c and 1.1c-associated groups occupied near half of archaeal 16S rRNA gene sequences in the $B$ horizon, but nearly all archaeal amo $A$ sequences from $B$ horizon fell into the 1.1a-associated group based on the classification in this study, while the only one remaining sequence AOAC-u_sA08 seems related to the $1.1 \mathrm{~b}$ group, thus, it is unlikely that the amoA genes were amplified from the 1.1c and 1.1c-associated groups. Some other primers, including CrenAmoAModF/CrenAmoAModR, CrenAmo AQ-F/CrenAmoAModR (Mincer et al., 2007) and Arch_amoA_F/Arch-amoAR (de la Torre et al., 2008), were tested but still failed to amplify amoA gene from the 1.1c-related groups although these primers seem to amplify archaeal amoA gene from broad phylogeny groups including strain Nitrosocaldus yellowstonii and ALOHA group (Mincer et al., 2007). Phylogeny of 1.1c, 1.1c-associated, 1.1a/b, Nitrosocaldus yellowstonii and ALOHA group were quite distant from each other (Fig. 6). However, it is surprising to some extent that phylogeny of Nitrosocaldus yellowstonii was close to the $1.1 \mathrm{~b}$ group with strong support based on the 16S rRNA gene analysis in this study (Fig. 4). Whether the 1.1c- and 1.1cassociated groups are amoA absent or the primers are biased needs to be elucidated, and more cautions should be given when quantifying AOA either based on 16S rRNA or amoA genes.

Sequences from the $1.1 \mathrm{a} / \mathrm{b}$ group had a unique T-RF of $322 \mathrm{bp}$, while T-RFs of 350, 352, 201 and $197 \mathrm{bp}$ belonged to the $1.1 \mathrm{c}$ or $1.1 \mathrm{c}$-associated group. Proportion of $322 \mathrm{bp}$ based on T-RFLP analysis correlated significantly $(r=0.867, P<0.001)$ with ratio of archaeal amoA/16S rRNA gene copy number, which further indicated that the amoA genes were amplified from the $1.1 \mathrm{a} / \mathrm{b}$ group. Since archaea were dominated by $1.1 \mathrm{a} / \mathrm{b}$ group in the restoration, cropland and pine plots where ratio of archaeal amoA/16S rRNA gene copy number was near three, it was implicated that the ratio of archaeal $16 \mathrm{~S}$ rRNA to amoA copy in cell might be 2-3.

In addition, most archaeal 16S rRNA sequences showed high similarities (>95\%) to some sequences reported by Hansel and colleagues (2008) such as ArcB_cA06, ArcC-u_cF02, ArcB_cB07, ArcC-u_cF02 and ArcC-u_cG02, which were also cloned from acidic soils, and suggested possible important effect of $\mathrm{pH}$ on archaeal communities as indicated above by amoA gene analysis.

\section{Conclusions}

Our results revealed significant effect of land utilization patterns on PNR, abundance of $\mathrm{AOB}$ and $\mathrm{AOA}$, and community structure of AOA. Greatest changes were found in the degradation or cropland plots for most parameters, which indicated profound influence of frequent human disturbance in soil properties and potential functions caused by reduced vegetation or agricultural practice. Significant correlation between AOB abundance and PNR suggested a potential important role of $A O B$ in nitrification in the red soil. The amoA gene was not amplified from 1.1c-related groups in this study, and further study is needed to clarify the phylogeny of $A O A$ and reduce the possible bias of PCR primers.

\section{Acknowledgements}

This work was supported by the Chinese Academy of Sciences (KZCX2-YW-JC401) and the Natural Science Foundation of China (40701087, 40871129, 40901121). We are grateful to Xiaoli Xie and others for access to the field site and assistance in soil sampling.

\section{References}

Avrahami, S., and Conrad, R. (2003) Patterns of community change among ammonia oxidizers in meadow soils upon long-term incubation at different temperatures. Appl Environ Microbiol 69: 6152-6164.

Beman, J.M., Popp, B.N., and Francis, C.A. (2008) Molecular and biogeochemical evidence for ammonia oxidation by marine Crenarchaeota in the Gulf of California. ISME J 2: 429-441.

Boyle-Yarwood, S.A., Bottomley, P.J., and Myrold, D.D. (2008) Community composition of ammonia-oxidizing bacteria and archaea in soils under stands of red alder and Douglas fir in Oregon. Environ Microbiol 10: 2956-2965.

Bruns, M.A., Stephen, J.R., Kowalchuk, G.A., Prosser, J.I., and Paul, E.A. (1999) Comparative diversity of ammonia oxidizer 16S rRNA gene sequences in native, tilled, and successional soils. Appl Environ Microbiol 65: 2994-3000.

Caffrey, J.M., Bano, N., Kalanetra, K., and Hollibaugh, J.T. (2007) Ammonia oxidation and ammonia-oxidizing bacteria and archaea from estuaries with differing histories of hypoxia. ISME J 1: 660-662.

Carney, K.M., Matson, P.A., and Bohannan, B.J.M. (2004) Diversity and composition of tropical soil nitrifiers across a plant diversity gradient and among land-use types. Ecol Lett 7: 684-694.

Chen, X.P., Zhu, Y.G., Xia, Y., Shen, J.P., and He, J.Z. (2008) Ammonia-oxidizing archaea: important players in paddy rhizosphere soil? Environ Microbiol 10: 1978-1987.

Compton, J.E., and Boone, R.D. (2000) Long-term impacts of agriculture on soil carbon and nitrogen in New England forests. Ecology 81: 2314-2330.

Delong, E.F. (1992) Archaea in coastal marine environments. Proc Natl Acad Sci USA 89: 5685-5689.

Di, H.J., Cameron, K.C., Shen, J.P., Winefield, C.S., O'Callaghan, M., Bowatte, S., and He, J.Z. (2009) Nitrifi- 
cation driven by bacteria and not archaea in nitrogen-rich grassland soils. Nature Geoscience 2: 621-624.

Francis, C.A., Roberts, K.J., Beman, J.M., Santoro, A.E., and Oakley, B.B. (2005) Ubiquity and diversity of ammoniaoxidizing archaea in water columns and sediments of the ocean. Proc Natl Acad Sci USA 102: 14683-14688.

Francis, C.A., Beman, J.M., and Kuypers, M.M. (2007) New processes and players in the nitrogen cycle: the microbial ecology of anaerobic and archaeal ammonia oxidation. ISME J 1: 19-27.

Ge, Y., He, J.Z., Zhu, Y.G., Zhang, J.B., Xu, Z.H., Zhang, L.M., and Zheng, Y.M. (2008) Differences in soil bacterial diversity: driven by contemporary disturbances or historical contingencies? ISME J 2: 254-264.

Hallam, S.J., Mincer, T.J., Schleper, C., Preston, C.M., Roberts, K., Richardson, P.M., and DeLong, E.F. (2006) Pathways of carbon assimilation and ammonia oxidation suggested by environmental genomic analyses of marine Crenarchaeota. PLoS Biol 4: 520-536.

Hansel, C.M., Fendorf, S., Jardine, P.M., and Francis, C.A. (2008) Changes in bacterial and archaeal community structure and functional diversity along a geochemically variable soil profile. Appl Environ Microbiol 74: 1620-1633.

Hatzenpichler, R., Lebedeva, E.V., Spieck, E., Stoecker, K., Richter, A., Daims, H., and Wagner, M. (2008) A moderately thermophilic ammonia-oxidizing crenarchaeote from a hot spring. Proc Natl Acad Sci USA 105: 2134-2139.

He, J.Z., Shen, J.P., Zhang, L.M., Zhu, Y.G., Zheng, Y.M., Xu, M.G., and Di, H.J. (2007) Quantitative analyses of the abundance and composition of ammonia-oxidizing bacteria and ammonia-oxidizing archaea of a Chinese upland red soil under long-term fertilization practices. Environ Microbiol 9: 2364-2374.

Hershberger, K.L., Barns, S.M., Reysenbach, A.L., Dawson, S.C., and Pace, N.R. (1996) Wide diversity of Crenarchaeota. Nature 384: 420.

Horz, H.-P., Barbrook, A., Field, C.B., and Bohannan, B.J.M. (2004) Ammonia-oxidizing bacteria respond to multifactorial global change. Proc Natl Acad Sci USA 101: 15136-15141.

Jia, Z.J., and Conrad, R. (2009) Bacteria rather than Archaea dominate microbial ammonia oxidation in an agricultural soil. Environ Microbiol 11: 1658-1671.

Kemnitz, D., Kolb, S., and Conrad, R. (2007) High abundance of Crenarchaeota in a temperate acidic forest soil. FEMS Microbiol Ecol 60: 442-448.

Könneke, M., Bernhard, A.E., Torre, J.R., Walker, C.B., Waterbury, J.B., and Stahl, D.A. (2005) Isolation of an autotrophic ammonia-oxidizing marine archaeon. Nature 437: 543-546.

Kowalchuk, G.A., and Stephen, J.R. (2001) Ammoniaoxidizing bacteria: a model for molecular microbial ecology. Annu Rev Microbiol 55: 485-529.

Kumar, S., Tamura, K., and Nei, M. (2004) MEGA3: integrated software for molecular evolutionary genetics analysis and sequence alignment. Brief Bioinform 5: 150-163.

Lam, P., Jensen, M.M., Lavik, G., McGinnis, D.F., Muller, B., Schubert, C.J., et al. (2007) Linking crenarchaeal and bacterial nitrification to anammox in the Black Sea. Proc Natl Acad Sci USA 104: 7104-7109.

Le Roux, X., Poly, F., Currey, P., Commeaux, C., Hai, B., Nicol, G.W., Prosser, J.I., Schloter, M., Attard, E., and
Klumpp, K. (2008) Effects of aboveground grazing on coupling among nitrifier activity, abundance and community structure. ISME J 2: 221-232.

Leininger, S., Urich, T., Schloter, M., Schwark, L., Qi, J., Nicol, G.W., Prosser, J.I., Schuster, S.C., and Schleper, C. (2006) Archaea predominate among ammonia-oxidizing prokaryotes in soils. Nature 442: 806-809.

Mincer, T.J., Church, M.J., Taylor, L.T., Preston, C., Karl, D.M., and Delong, E.F. (2007) Quantitative distribution of presumptive archaeal and bacterial nitrifiers in Monterey Bay and the North Pacific Subtropical Gyre. Environ Microbiol 9: 1162-1175.

Nicol, G.W., Campbell, C.D., Chapman, S.J., and Prosser, J.I. (2007) Afforestation of moorland leads to changes in crenarchaeal community structure. FEMS Microbiol Ecol 60: 51-59.

Nicol, G.W., Leininger, S., Schleper, C., and Prosser, J.I. (2008) The influence of soil pH on the diversity, abundance and transcriptional activity of ammonia oxidizing archaea and bacteria. Environ Microbiol 10: 2966-2978.

Phillips, C.J., Harris, D., Dollhopf, S.L., Gross, K.L., Prosser, J.I., and Paul, E.A. (2000) Effects of agronomic treatments on structure and function of ammonia-oxidizing communities. Appl Environ Microbiol 66: 5410-5418.

Prosser, J.I., and Embley, T.M. (2002) Cultivation-based and molecular approaches to characterisation of terrestrial and aquatic nitrifiers. Antonie van Leeuwenhoek 81: 165-179.

Prosser, J.I., and Nicol, G.W. (2008) Relative contributions of archaea and bacteria to aerobic ammonia oxidation in the environment. Environ Microbiol 10: 2931-2941.

Purkhold, U., Pommerening-Roser, A., Juretschko, S., Schmid, M.C., Koops, H.-P., and Wagner, M. (2000) Phylogeny of all recognized species of ammonia oxidizers based on comparative $16 \mathrm{~S}$ rRNA and amoA sequence analysis: implications for molecular diversity surveys. Appl Environ Microbiol 66: 5368-5382.

Rotthauwe, J.H., Witzel, K.P., and Liesack, W. (1997) The ammonia monooxygenase structural gene amoA as a functional marker: molecular fine-scale analysis of natural ammonia-oxidizing populations. Appl Environ Microbio/63: 4704-4712.

Shen, J.P., Zhang, L.M., Zhu, Y.G., Zhang, J.B., and He, J.Z. (2008) Abundance and composition of ammonia-oxidizing bacteria and ammonia-oxidizing archaea communities of an alkaline sandy loam. Environ Microbiol 10: 1601-1611.

de la Torre, J.R., Walker, C.B., Ingalls, A.E., Könneke, M., and Stahl, D.A. (2008) Cultivation of a thermophilic ammonia oxidizing archaeon synthesizing crenarchaeol. Environ Microbiol 10: 810-818.

Tourna, M., Freitag, T.E., Nicol, G.W., and Prosser, J.I. (2008) Growth, activity and temperature responses of ammoniaoxidizing archaea and bacteria in soil microcosms. Environ Microbiol 10: 1357-1364.

Treusch, A.H., Leininger, S., Kletzin, A., Schuster, S.C., Klenk, H.-P., and Schleper, C. (2005) Novel genes for nitrite reductase and Amo-related proteins indicate a role of uncultivated mesophilic crenarchaeota in nitrogen cycling. Environ Microbiol 7: 1985-1995.

Wuchter, C., Abbas, B., Coolen, M.J.L., Herfort, L., van Bleijswijk, J., Timmers, P., et al. (2006) Archaeal nitrification in the ocean. Proc Natl Acad Sci USA 103: 12317-12322. 